This document was prepared in conjunction with work accomplished under Contract No. DE-AC09-96SR18500 with the U.S. Department of Energy.

This work was prepared under an agreement with and funded by the U.S. Government. Neither the U. S. Government or its employees, nor any of its contractors, subcontractors or their employees, makes any express or implied: 1 . warranty or assumes any legal liability for the accuracy, completeness, or for the use or results of such use of any information, product, or process disclosed; or 2 . representation that such use or results of such use would not infringe privately owned rights; or 3 . endorsement or recommendation of any specifically identified commercial product, process, or service. Any views and opinions of authors expressed in this work do not necessarily state or reflect those of the United States Government, or its contractors, or subcontractors. 


\title{
INTEGRATED PROCESS GAS MODELING FOR TRITIUM SYSTEMS AT THE SAVANNAH RIVER SITE
}

\author{
A. S. Poore and T. Hang \\ Savannah River National Laboratory, Washington Savannah River Company, Aiken, SC 29808 USA \\ anita.poore@srnl.doe.gov and thong.hang@srnl.doe.gov
}

\begin{abstract}
Significant savings are being realized from the consolidated tritium gas-processing operations at the Savannah River Site. However, the trade-off is some reduction of operational flexibility due to decreased storage capacity for process and waste gases. Savannah River National Laboratory researchers are developing an integrated process gas model for tritium processing using Aspen Custom Modeler ${ }^{\mathrm{TM}}$ (ACM) software. The modeling involves fully characterizing process flow streams (gas composition, quantity), frequency of batch transfers, and availability of equipment in the flow stream. The model provides a valuable engineering tool to identify flow bottlenecks, thereby enabling adjustments to be made to improve process operations.
\end{abstract}

\section{INTRODUCTION}

Researchers at the Savannah River National Laboratory (SRNL) are developing an integrated secondary process gas flow sheet model for tritium processing using Aspen Custom Modeler ${ }^{\mathrm{TM}}$ (ACM) software to help optimize the operational efficiency of the Tritium Facility's new gas-handling processes. The modeling involves fully characterizing all process flow streams (gas composition, quantity), frequency of batch transfers, and availability of equipment in the flow stream. The model provides a valuable engineering tool to identify flow bottlenecks, thereby enabling adjustments to be made to improve process operations.

The Tritium Facilities at the Savannah River Site (SRS) have consolidated tritium gas processing operations within the past five years. All of the waste gas processing is now handled by new systems placed in an existing facility. ${ }^{1}$ The initial tritium gas processing model focuses on the following tritium gas processing systems: Tritium Process Stripper (TPS), Special Container Loading and Unloading (SCLU), Z-Bed Recovery (ZBR), and Hydrogen-Tritium Thermal Cycling Absorption Process (HT-TCAP) operations. These secondary tritium gas processes were selected since they have the highest potential to improve operating process efficiencies. Design basis information for each of the selected tritium gas processing systems was used to create the process gas model. Test scenarios demonstrate the model capabilities to simulate integrated plant operations.

\section{TRITIUM FACILITIES GAS FLOW SHEET OF SECONDARY PROCESSES}

The secondary tritium gas processing systems in the Tritium Facilities at SRS include the TPS, HT-TCAP, ZBR, SCLU, and Nitrogen Evacuation (N-Evac). Other secondary tritium gas processes not addressed in the process model, include process glove boxes, glove box strippers, and other test systems. The flow diagram of the secondary tritium gas processes are shown in Fig. 1.

The inert-rich (mainly nitrogen, helium) gas streams are collected primarily in the N-Evac tanks, and then processed by the TPS system. Detritiated inert gases are then released to the environment via the stack. TPS also processes ZBR tanks that contain high concentrations of inert gases. The hydrogen-rich (protium, deuterium, tritium) gas streams are processed by the HT-TCAP system. The high purity tritium and/or deuterium are returned to the primary tritium gas processes, and the detritiated protium (or deuterium) is released to the environment via the stack. SCLU is mainly an unloading system for Hydride Transport Vessels (HTVs) and Hydride Storage Vessels (HSVs). Other vessels unloaded in SCLU include St-198 bed and Product Vessels (PVs). Loading capability is provided in SCLU, but is used infrequently and will not be modeled.

The secondary process model was derived from the design-basis system components. The design modifications to the TPS and HT-TCAP systems have been incorporated into the process model. In many cases, simplified component operations (split factors, efficiencies) have been used to develop the current secondary process model. Operational information such as setup and process times, flow and gas stream characteristics, etc. are planned to be added at a later date to more completely represent the operating systems. 


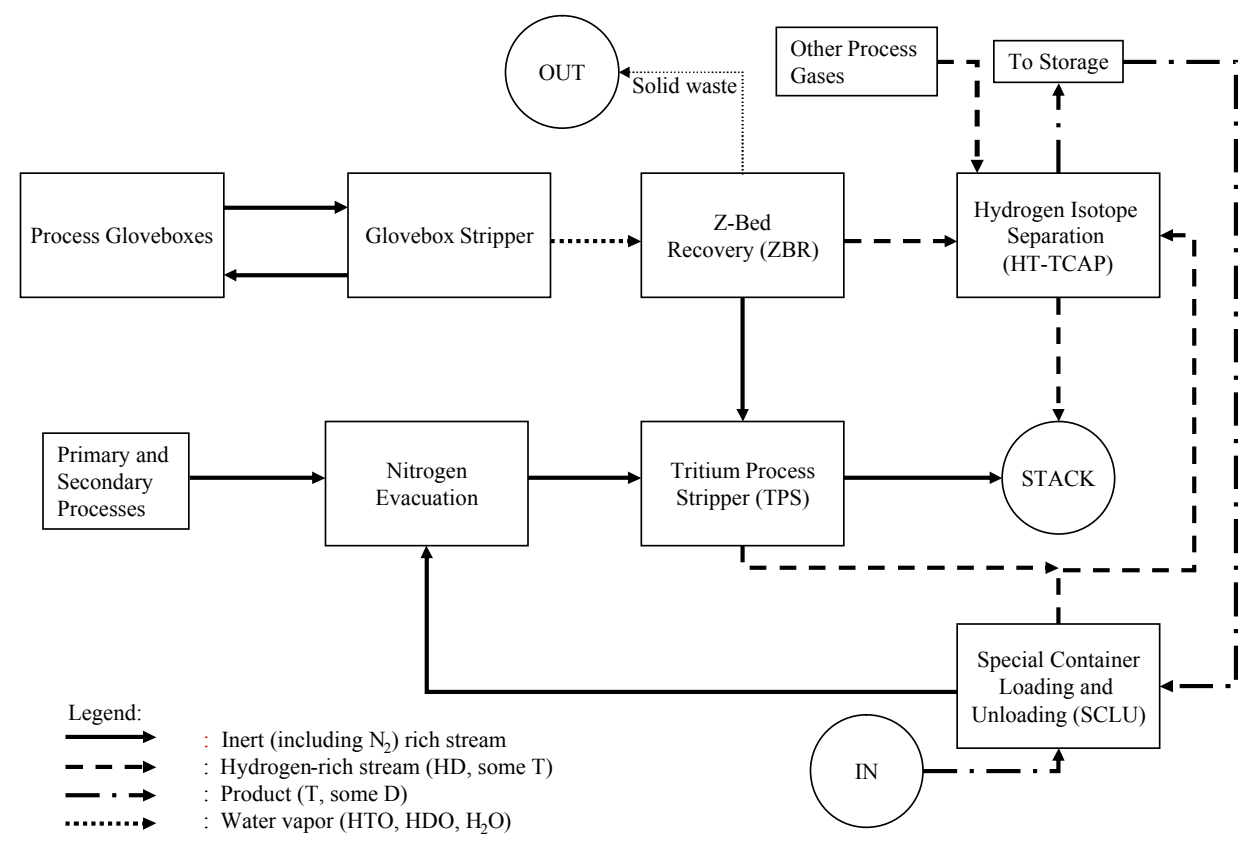

Fig. 1. Flow Diagram of the Secondary Tritium Gas Processes

\section{MODEL DEVELOPMENT}

\section{III.A. ACM Modeling}

In the early stage of this modeling project, Extend $V$. 6 software licensed from Imagine That, Inc. was considered as the process simulation platform to develop the Tritium Gas Flow Sheet model for the secondary processes. However, developmental testing quickly showed that Extend, though widely used for manufacturing and operations modeling and simulation, is not the right tool for the tritium process model that is required to include full characterization of all process streams (e.g., chemical composition, quantity etc.) and possible chemical reactions in some operation units. The current Extend capabilities do not satisfy these requirements.

The Aspen Custom Modeler ${ }^{\mathrm{TM}}$ (ACM) software marketed by Aspen Technology, Inc. for chemical process modeling was therefore selected. The architecture of ACM makes it well suited to modeling both continuous and/or batch operations. With ACM, models may be developed in phases by adding more complex features over time. For accuracy, physical properties of compounds and mixtures are predicted using Aspen Properties Plus ${ }^{\circledR}$ bundled with ACM. Chemical reactions, if any, may be specified and implemented. Complex ACM models have been successfully developed by SRNL researchers in the past. ${ }^{2,3}$

\section{III.B. Chemical Component List}

Table I provides the list of chemical components currently included in the model. These chemical compounds comprise the majority of the gas streams. ${ }^{1}$ Note $\mathrm{N}_{2}, \mathrm{Ar}$, and $\mathrm{He}$ are grouped together and represented by the INERT component. ACM is structured such that more chemical components, if required, can be easily added to the model.

TABLE I. Chemical Compounds Included in the Tritium Gas Processing Model

\begin{tabular}{|l|}
\hline $\mathrm{H}_{2}$ \\
\hline $\mathrm{D}_{2}$ \\
\hline $\mathrm{T}_{2}$ \\
\hline $\mathrm{O}_{2}$ \\
\hline $\mathrm{CH}_{4}$ \\
\hline $\mathrm{CH}_{3} \mathrm{~T}$ \\
\hline $\mathrm{CO}$ \\
\hline $\mathrm{CO}_{2}$ \\
\hline $\mathrm{INERT}$ \\
\hline $\mathrm{H}_{2} \mathrm{O}$ \\
\hline
\end{tabular}

\section{III.C. Model Flow Sheet}

The ACM flow sheet includes the hierarchy blocks for the TPS, HT-TCAP, ZBR, N-EVAC and SCLU Systems. Flow sheet hierarchy is an ACM feature that helps manage the complexity of a large flow sheet by splitting it up into a number of sub flow sheets. Each hierarchy block therefore represents a sub flow sheet. In 
the current version, the model handles connections between hierarchy blocks (e.g., to transfer feeds from one block to another) by using the ACM tasks to assign process variable/parameter values between components of different blocks.

\section{TEST SCENARIOS}

The purpose of the test scenarios is to demonstrate the model capabilities to simulate actual plant operations. At this stage of development, the focus is more on functionalities than on numerical accuracy of calculations. Three cases were developed to test the integrated operations of the Secondary Process Systems:

1. Case 1: Test the ZBR System and the HT-TCAP System.

2. Case 2: Test the ZBR System, the TPS System, and the HT-TCAP System.

3. Case 3: Test the HSV Unloading in the SCLU System and the HT-TCAP System

All test cases clearly showed that the model successfully simulates the integrated operations of the Secondary Process Systems. For demonstration, Test Case 1 is presented in detail below.

\section{IV.A. Case 1: Test the ZBR System and the HT-TCAP System}

Case 1 assumes that a large feed volume of 5,000 liters is to be processed through the ZBR System until the Recovery Tank is full. The ZBR feed is mostly made up of water vapor with some traces of tritium. Since the Recovery Tank contained a low nitrogen concentration (assumed $<2$ vol. \%), its content is transferred to the HTTCAP System after passing through the dryer zeolite bed for further moisture removal producing a dry gas. ZBR recovered gas is subsequently allocated to the hydride storage feed bed in the HT-TCAP System and processed through the system to generate raffinate (stack gas) and product.

The modeling of Case 1 is carried out according to the operational sequence given in Table 2. The model inputs for Case 1 are specified in Table 3. As shown in Table 4, the model predicts the ZBR recovered gas with low nitrogen (Inert) concentration (i.e., 0.23\%) and negligible moisture content $(<1 \mathrm{ppm})$. HT-TCAP processes the ZBR recovered gas to produce a stack gas stream of $0.23 \mathrm{ppm}$ tritium and a product stream that contains $48 \%$ tritium.
TABLE 2. Case 1 Operational Steps

\begin{tabular}{ll} 
Step No. & Operation Description \\
\hline 1 & ZBR process setup \\
2 & $\begin{array}{l}\text { Process the ZBR feed until the Recovery } \\
\text { Tank is full } \\
\text { Transfer the Recovery Tank content to HT- } \\
3\end{array}$ \\
& $\begin{array}{l}\text { TCAP } \\
\text { Assign the HT-TCAP gas to the hydride } \\
\text { storage feed bed }\end{array}$ \\
5 & HT-TCAP process setup \\
6 & $\begin{array}{l}\text { Check if the required HT-TCAP } \\
\text { components are available for operation }\end{array}$ \\
7 & Process hydride storage feed bed through \\
& HT-TCAP Column until bed is empty
\end{tabular}

TABLE 3. Case 1 System Input Specifications

\begin{tabular}{|c|l|}
\hline ZBR Feed Composition & \\
(Volume Fraction) & 0. \\
$\mathrm{H}_{2}$ & 0. \\
$\mathrm{D}_{2}$ & 0.0002 \\
$\mathrm{~T}_{2}$ & 0. \\
$\mathrm{O}_{2}$ & 0.005 \\
$\mathrm{CH}_{4}$ & 0. \\
$\mathrm{CH}_{3} \mathrm{~T}$ & 0. \\
$\mathrm{CO}$ & 0. \\
$\mathrm{CO}_{2}$ & 0.0010 \\
$\left.\mathrm{INERT}_{\mathrm{N}} \mathrm{N}_{2}+\mathrm{He}+\mathrm{Ar}\right)$ & 0.9938 \\
$\mathrm{H}_{2} \mathrm{O}$ & \\
ZBR Operational Parameters & $5,000.00$ \\
\hline Batch volume (L) & 24 \\
Setup time (hr) & 10 \\
Feed rate (L/min) & 20 \\
Moisture in gas flow to Mg-Bed $(\%)$ & 98 \\
Mg-Bed $\mathrm{H}_{2} \mathrm{O}$ cracking efficiency $(\%)$ & 10 \\
Maximum recycle rate (L/min) & 581 \\
Recovery Tank volume (gallons) & 99.99 \\
Z-Bed $\mathrm{H}_{2} \mathrm{O}$ removal efficiency (\%) & \\
\hline HT-TCAP Operational Parameters & 0.5 \\
\hline LTFB feed rate (L/min) & 99.95 \\
Column D stripping efficiency (\%) & \\
\hline
\end{tabular}

TABLE 4. Case 1 Calculated Result

\begin{tabular}{|l|ccc|}
\cline { 2 - 4 } \multicolumn{1}{c|}{} & $\begin{array}{c}\text { ZBR } \\
\text { Recovered } \\
\text { Gas to HT- } \\
\text { TCAP } \\
\text { (Volume }\end{array}$ & $\begin{array}{c}\text { HT-TCAP } \\
\text { Stack Gas } \\
\text { (Volume } \\
\text { Fraction) }\end{array}$ & $\begin{array}{c}\text { HT-TCAP } \\
\text { Product } \\
\text { (Volume } \\
\text { Fraction) }\end{array}$ \\
\hline $\mathrm{H}_{2}$ & 0.98567 & 0.98612 & 0.51618 \\
$\mathrm{D}_{2}$ & 0.00000 & 0.00000 & 0.00000 \\
$\mathrm{~T}_{2}$ & $4.62 \mathrm{E}-04$ & $2.31 \mathrm{E}-07$ & 0.48382 \\
$\mathrm{O}_{2}$ & 0.00000 & 0.00000 & 0.00000 \\
$\mathrm{CH}_{4}$ & 0.01155 & 0.01156 & 0.00000 \\
$\mathrm{CH}_{3} \mathrm{~T}$ & 0.00000 & 0.00000 & 0.00000
\end{tabular}




\begin{tabular}{|l|ccc|}
$\mathrm{CO}$ & 0.00000 & 0.00000 & 0.00000 \\
$\mathrm{CO}_{2}$ & 0.00000 & 0.00000 & 0.00000 \\
$\mathrm{INERT}$ & 0.00231 & 0.00231 & 0.00000 \\
$\mathrm{H}_{2} \mathrm{O}$ & $3.98 \mathrm{E}-07$ & $3.99 \mathrm{E}-07$ & 0.00000 \\
\hline
\end{tabular}

Figures 2 and 3 illustrate the ZBR and HT-TCAP operation, respectively. In Fig. 2, after an initial process setup, the ZBR System begins to process the feed indicating a decrease in the feed volume and an increase in the Recovery Tank volume over time. During the process the gas stream leaving the $\mathrm{Mg}$ Bed is partially recycled back to the feed bed as presented by the Recycle Flow graph. In the water trap unit, water first condenses due to moisture excess in the gas flow, hence resulting in an increase in the water trap holdup volume. As time progresses, insufficient moisture in the gas flow requires more evaporation of trapped water, thus causing the decrease in the water trap volume. Upon depletion of the feed, the Recovery Tank gas passes through the drying zeolite bed for additional moisture removal and the dry gas is sent to HT-TCAP causing an increase in the HTTCAP gas volume. In Fig. 3, the HT-TCAP System begins after $\sim 80$ hours when the ZBR operation is completed. The ZBR recovered gas is stored in a hydride storage bed until it is scheduled to be processed through HT-TCAP. HT-TCAP operates until the hydride storage bed becomes empty. The HT-TCAP column generates a stack gas (raffinate) flow and a product flow.

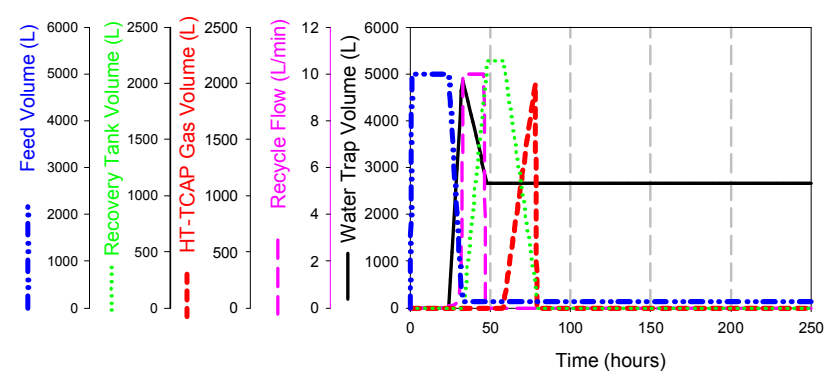

Fig. 2. ZBR Operation

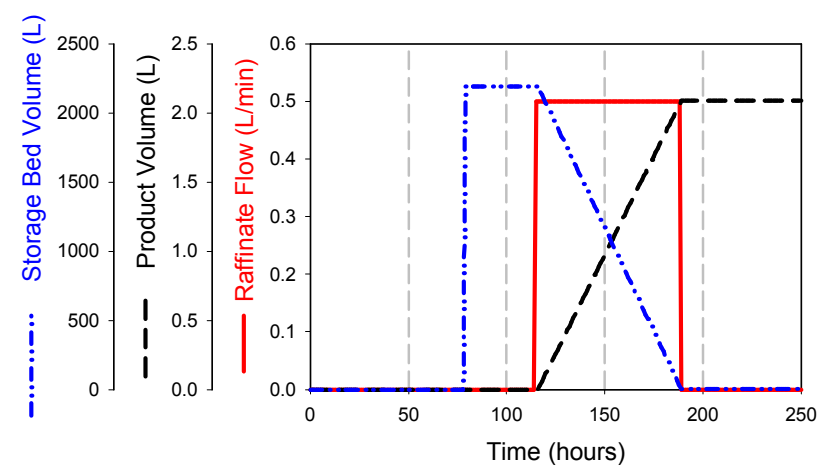

Fig. 3. HT-TCAP Operation

\section{CONCLUSIONS}

Using the Aspen Custom Modeler ${ }^{\mathrm{TM}}$ (ACM) software, SRNL researchers developed an integrated secondary process gas flow sheet model for tritium processing. The model involves all process flow stream characteristics (gas composition, quantity), frequency of batch transfers, and availability of equipment in the flow stream. The current version of the model includes the main operation systems of the tritium secondary processes. Overall and component volume balances are accounted for in each operation unit. The ACM event-driven tasks are fully utilized to allow the model to simulate typical batch operations (e.g., process setup, down-time, batch transfers etc.). Verification of the model by comparing the model computed results with the design basis calculations showed excellent agreement for all calculations. Three test scenarios were developed to demonstrate the model capabilities to simulate actual plant operations. All test cases clearly showed that the model successfully simulates the integrated operations of the Secondary Process Systems.

\section{ACKNOWLEDGMENTS}

The authors thank L. K Heung and J. E. Klein of the Savannah River National Laboratory, and G. R. Griswold, K. L. Sessions, J. L. Clark and A. M. Jwayyed of the Defense Programs division for their valuable assistance and contributions to this paper. This report was prepared by Washington Savannah River Company (WSRC) for the United States Department of Energy under Contract No. DE-AC09-96SR18500 and is an account of work performed under that contract.

\section{REFERENCES}

1. A. S. POORE and W. D. JACOBS, "New Systems for Waste Processing of Tritium-Containing Gases at the Savannah River Site." Fusion Science and Technology, 48, July/August 2005.

2. T. HANG and D. D. WALKER, "Prediction of Gas Generation and Bubble Formation in Crystalline Silicotitanate Ion Exchange Columns," Proceedings of the 2001 Advanced Simulation Technologies Conference (ASTC'01), Seattle, Washington, April 22-26, 2001, p. 63, The Society for Modeling and Simulation International.

3. T. HANG, M. B. GORENSEK and L. D. KOFFMAN, "Modeling of the Savannah River Site High Level Waste Evaporator Systems," Proceedings of the 2003 Advanced Simulation Technologies Conference (ASTC'03), Orlando, Florida, March 30 April 3, 2003, p. 71, The Society for Modeling and Simulation International. 
WSRC-STI-2007-00154

August 24, 2007

Keywords: $\quad$ Tritium

\title{
Integrated Process Gas Modeling for Tritium Systems at the Savannah River Site
}

\author{
A. S. Poore and T. Hang \\ Savannah River National Laboratory, Westinghouse Savannah River Company, Aiken, SC 29808 USA \\ anita.poore@ssrnl.doe.gov and thong.hang@ssrnl.doe.gov
}

Paper prepared for

Tritium 2007: 8th International Symposium on Tritium Science and Technology

Rochester, NY USA

September 16-21, 2007

And to be published in Fusion Science and Technology 